OPEN ACCESS

Edited by:

Mohammad Amjad Kamal, King Abdulaziz University,

Saudi Arabia

Reviewed by:

Tanveer Ali Dar, University of Kashmir, India Christian Gonzalez-Billault,

University of Chile, Chile

*Correspondence: Inho Choi inhochoi@ynu.ac.kr

tThese authors have contributed equally to this work.

${ }^{\ddagger}$ Present address: Arif Tasleem Jan, School of Biosciences and Biotechnology, Baba Ghulam Shah Badshah University, Rajouri, India

Received: 28 April 2017 Accepted: 15 September 2017 Published: 29 September 2017

Citation: Jan AT, Malik MA, Rahman S, Yeo HR, Lee EJ, Abdullah TS and Choi I (2017) Perspective Insights of

Exosomes in Neurodegenerative Diseases: A Critical Appraisal.

Front. Aging Neurosci. 9:317. doi: 10.3389/fnagi.2017.00317

\section{Perspective Insights of Exosomes in Neurodegenerative Diseases: A Critical Appraisal}

\author{
Arif Tasleem Jan ${ }^{1+\neq}$, Mudasir A. Malik ${ }^{2 \dagger}$, Safikur Rahman ${ }^{1}$, Hye R. Yeo ${ }^{1}$, Eun J. Lee ${ }^{1}$, \\ Tasduq S. Abdullah ${ }^{2}$ and Inho Choi ${ }^{1 *}$
}

${ }^{1}$ Department of Medical Biotechnology, Yeungnam University, Gyeongsan, South Korea, ${ }^{2}$ CSIR-Indian Institute of Integrative Medicine, Jammu, India

Exosomes are small membranous entities of endocytic origin. Their production by a wide variety of cells in eukaryotes implicates their roles in the execution of essential processes, especially cellular communication. Exosomes are secreted under both physiological and pathophysiological conditions, and their actions on neighboring and distant cells lead to the modulations of cellular behaviors. They also assist in the delivery of disease causing entities, such as prions, $\alpha$-syn, and tau, and thus, facilitate spread to non-effected regions and accelerate the progressions of neurodegenerative diseases. The characterization of exosomes, provides information on aberrant processes, and thus, exosome analysis has many clinical applications. Because they are associated with the transport of different cellular entities across the blood-brain barrier (BBB), exosomes might be useful for delivering drugs and other therapeutic molecules to brain. Herein, we review roles played by exosomes in different neurodegenerative diseases, and the possibilities of using them as diagnostic biomarkers of disease progression, drug delivery vehicles and in gene therapy.

Keywords: diagnostics, drugs, exosomes, neurodegeneration, therapeutics

\section{INTRODUCTION}

Exosomes were first considered to be vesicles produced by mature blood reticulocytes and secreted into extracellular milieu with topically expressed transferrin receptors (Harding and Stahl, 1983; Johnstone et al., 1987). Unlike microvesicles, which arise from outward budding of plasma membrane, apoptotic bodies (fragments of dying cells), and ectosomes, exosomes are produced by the fusion of multivesicular bodies (MVBs) with membranes. Exosomes are homogenous and smaller than other extracellular vesicles, with sizes ranging between 30-100 $\mathrm{nm}$ (Raposo and Stoorvogel, 2013; Keerthikumar et al., 2015). They are secreted by reticulocytes, mesenchymal cells, neurons, fibroblasts, epithelial cells, endothelial cells, platelets, allophycocyanins (APCs), tumor cells and other cells (Bobrie et al., 2011; Colombo et al., 2014), and are present in bronchioalveolar lavage, synovial fluid, urine, bile, breast milk, serum and other body fluids (Théry et al., 2009; Vlassov et al., 2012) because they display specific cell-derived components on their surfaces, exosomes with different cellular backgrounds possess same set of molecules, such as, enzymes, nucleic acids, cytokines and bioactive compounds. Following release, they are uptaken by surrounding cells or transported systemically in cerebrospinal fluid (CSF; Grapp et al., 2013; Gui et al., 2015), breast milk (Zonneveld et al., 2014), blood (Baranyai et al., 2015), urine (Royo et al., 2016) and in other biological fluids to provide a means of cell-to-cell communication (Bang and Thum, 2012). Accordingly, exosomes influence physiological and pathobiological conditions. 
Exosome discovery has exhibited enormous growth over the past three decades. Once known primarily for their role in eliminating excessive cellular proteins and undesirable molecules, exosomes are now known to be required for many physiological processes, such as, the maintenance of normal physiological functions and cell-to-cell communication, and to play important roles in the progression of diseases, such as, cancer and neurodegenerative diseases. Their involvement in neurodegenerative disease progression are attributed to their abilities to transfer biomolecules and pathogenic entities across biological barriers (Candelario and Steindler, 2014; Thompson et al., 2016). Furthermore, their abilities to transport proteins and nucleic acids (siRNA, miRNA) have been exploited for the delivery of drugs and other encapsidated biomolecules. Here, we describe the roles of exosomes in the progressions of neurogenerative disorders, their diagnostic roles as neurodegeneration markers, and their therapeutic applications for the treatment of diseases and for gene therapy.

\section{EXOSOME COMPOSITIONS}

Technological advances have resulted in new ways of isolating exosomes by centrifugation, immunocapture and by using microfluidic methods, based on size, shape, density and surface marker expression. Although no consensus has been reached regarding isolation methods, immunoaffinity capture (IAC), chromatography, density gradient centrifugation and ultracentrifugation are the methods more commonly used (Skog et al., 2008). Exosome compositions are dictated by the functional states of cells (Bang and Thum, 2012), though their compositions are largely dependent on their origins (Cosme et al., 2013). Analyses of their compositions by Western blotting (Raposo et al., 1996), Fluorescence Activated Cell Sorting (FACS; Clayton et al., 2001) and mass spectrometry have revealed the presence of endosome associated proteins (Alix, TSG101), a series of tetraspanins (CD9, CD26, CD53, CD63, CD81, CD82), heat shock proteins (HsP70, Hsp90), cytoskeletal elements (tubulin, actin), clathrin, follitin-1, annexins, lysosomal protein (Lamp2b), $\mathrm{RAB}$ proteins, intercellular adhesion molecule-1 (ICAM-1), major histocompatibility complexes (MHCs), and co-stimulatory molecules of T-cells, like CD86 (Théry et al., 2002; Keller et al., 2006; Table 1). Proteomic analysis of exosomes also revealed the presence of cell surface anchored sheddases (e.g., ADAM, a disintegrin and metalloproteinase) and cell surface and soluble matrix metalloproteinases (MMPs; Théry et al., 2002). In addition to their extracellular matrix (ECM) remodeling roles, MMPs are critical in cellular interaction, proteosomal processing of exosomal contents and in the intercellular communication. Additionally, protein components, such as, peroxidases and pyruvate kinases, have also been reported in exosomes of enterocyte and human dendritic cells (Théry et al., 2002).

Exosomal membranes are also enriched with lipids, such as, ceramides, phosphatidyl ethanolamine, phosphatidylserine, diacylglyceride, cholesterol, lyso-bis-phosphatidic acid and sphingomyelin (Janas et al., 2015; Haraszti et al., 2016). Although characterization of exosomes depends on the cell type and the protocol used, exosomes have been reported to contain different amounts of DNA (dsDNA, ssDNA, MtDNA), RNA (mRNAs, miRNAs, snRNA, ncRNA) and small cytoplasmic RNAs (van Balkom et al., 2015; Zhang et al., 2015; Kalluri and LeBleu, 2016). Data pertaining to exosomes has been collated in the Exocarta ${ }^{1}$ database, which contains 41,860 proteins, 4956 mRNAs and 1116 miRNAs.

${ }_{1}$ www.exocarta.org

TABLE 1 | Table summarizing information on exosomal components.

\begin{tabular}{|c|c|c|}
\hline Constituents & Type & Function \\
\hline $\begin{array}{l}\text { Alix, TSG101, Rab proteins (Rab11, Rab27b), } \\
\text { VAMP7 }\end{array}$ & MVB formation & $\begin{array}{l}\text { Proteins involved in multivesicular } \\
\text { (MVB) biogenesis }\end{array}$ \\
\hline CD9, CD26, CD53, CD63,CD81, CD82 & Tetraspannins & $\begin{array}{l}\text { Morphogenesis, fission and fusion } \\
\text { processes }\end{array}$ \\
\hline Hsc70, Hsp 90 & $\begin{array}{l}\text { Heat-shock } \\
\text { proteins }\end{array}$ & Inherent characteristic of exosomes \\
\hline GTPases, clathrin and flotillin & Membrane transport and fusion proteins & $\begin{array}{l}\text { Membrane transport and fusion } \\
\text { proteins }\end{array}$ \\
\hline Actin, Tubulin and Annexins & Cytoskeletal elements & Structural \\
\hline $\begin{array}{l}\text { Metabolic enzymes (peroxidases, lipid and Pyruvate } \\
\text { kinases, etc.) }\end{array}$ & Metabolism & Regulation of metabolic activity \\
\hline$m R N A, \operatorname{miRN} A$, SnRNA & Genetic material & Gene expression regulation \\
\hline $\begin{array}{l}\text { Ceramides, phosphatidylserine, diacylglyceride, } \\
\text { cholesterol, Phosphatidylcholine, sphingomyelin, } \\
\text { etc. }\end{array}$ & Phospholipids and cholesterol & $\begin{array}{l}\text { Required for signaling and fusion to } \\
\text { cell membrane }\end{array}$ \\
\hline $\begin{array}{l}\text { MHC molecules, ICAM-1, CD86, P-selectin, } \\
\text { immunoglobulin } A 33\end{array}$ & Immune function & $\begin{array}{l}\text { Regulation of immune response } \\
\text { (immunosuppressive/immune } \\
\text { activation) }\end{array}$ \\
\hline $\begin{array}{l}\text { Transmembrane proteins such as } \alpha M \text { (DCs), } \alpha 4 \beta 1 \\
\text { (reticulocytes) }\end{array}$ & Signaling & $\begin{array}{l}\text { Cell specific exosome recognition } \\
\text { and characterization }\end{array}$ \\
\hline
\end{tabular}

The table contains information of proteins, nucleic acid and lipid components along with the role they play in exosomes. 


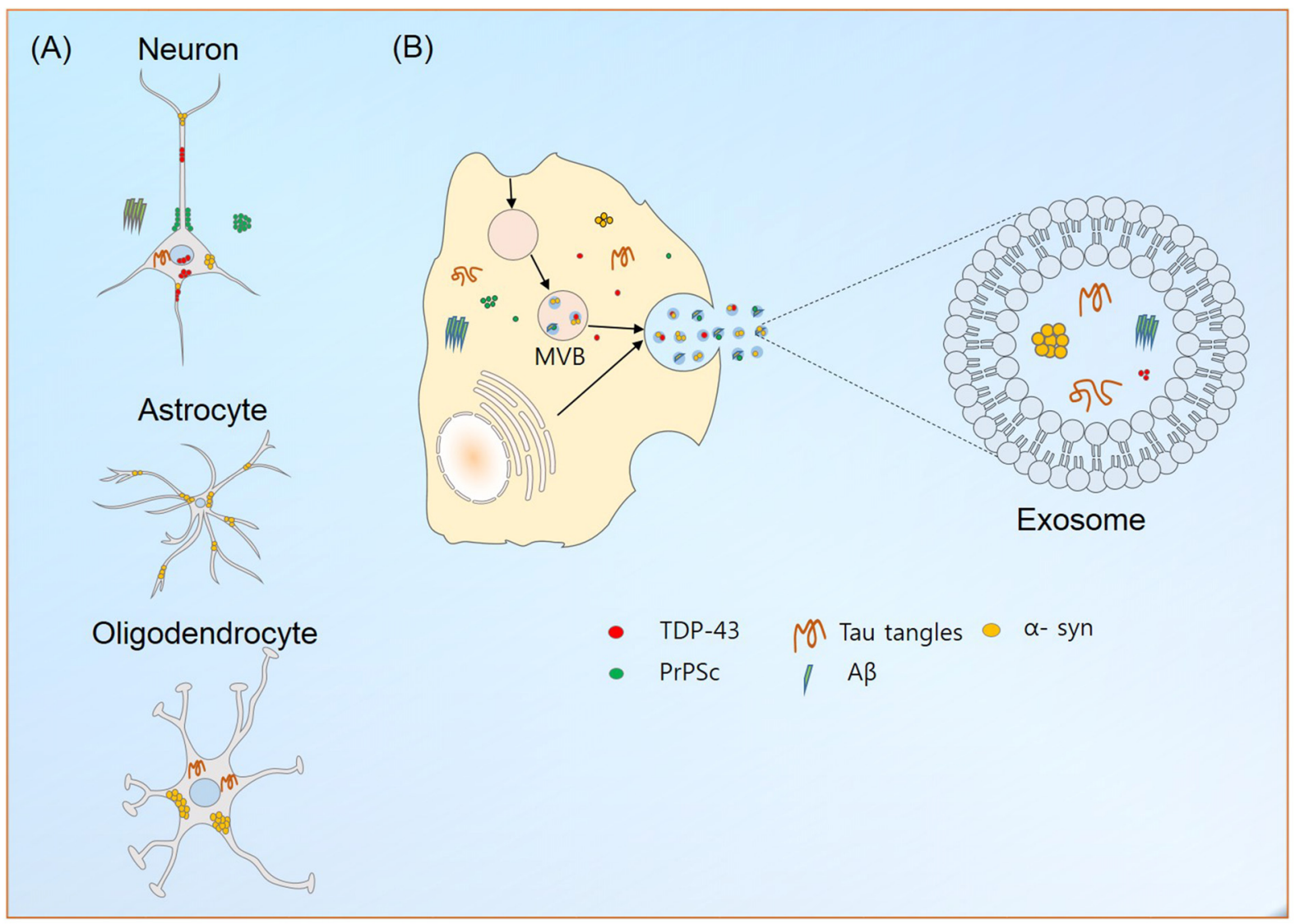

FIGURE 1 | Exosome production and neurodegeneration. (A) Localization of aggregated or misfolded proteins credited for their roles in the neurodegeneration in different neuronal cells. (B) Exosome production in neuronal cells. The abilities of exosomes to carry disease causing entities to neighboring and distant localized cells contributes to the aggravation of neurological diseases. Similarly, their transport across blood brain barrier (BBB) helps in reducing the possible emergence of different neurological diseases.

\section{EXOSOMES AND NEURODEGENERATION}

Exosome secretion has been reported for a number of cells in the nervous system (Figure 1A). Though exosomes from neurons display GluR2/3 subunit receptor molecules, microglia exosomes contain pro-inflammatory cytokine, IL- $\beta$, astrocytes Hsp70, IL- $\beta$ and synapsin- 1 and exosomes from oligodendrocytes contain myelin lipids: cholesterol, galactocerebrosides (Bianco et al., 2009; Kettenmann et al., 2011; Wang et al., 2011). Exosomes have a great effect on cell-tocell communication, due to: (1) interactions between topical proteins and receptors on target cells; and (2) proteolysis of their cargoes and internalizations of their contents via endocytosis. Furthermore, they allow intercellular communications, via the transport of protein and nucleic acid entities under both normal and diseased states, which suggests exosomes participate in development, cellular function and associated pathologies.

Aggregation of proteins is a hallmark of neurodegenerative diseases, and their accumulations in the CNS hinder mitochondrial and proteosomal functions, axonal transport and synaptic transmission and enhance endoplasmic reticulum stress (Joshi et al., 2014; Yuyama et al., 2015). The ability of exosomes to carry misfolded or aggregated proteins enhances the progression of neurodegenerative diseases (Figure 1B). In line with the prion-like spreading hypothesis (Prusiner, 1982), their implications in the transmission of infectious particles, prions (in Creutzfeldt-Jakob disease, CJD), amyloid precursor protein (APP; in Alzheimer's disease (AD)), $\alpha$-synuclein ( $\alpha$-syn; in Parkinson's disease (PD)) and superoxide dismutase 1 (SOD1; in amyotrophic lateral sclerosis (ALS)) between cells in the nervous system are currently being explored.

\section{Prion Diseases}

Prions are infectious particles that arise due to misfolded or aberrant conformations of proteins (Kupfer et al., 2009; Moore et al., 2009). Given an ability to transfer misfolded states to native forms of similar proteins, the proteopathic state of prions triggers a series of refoldings and aggregations, causing aggregations to oligomers and fibrils (Polymenidou and Cleveland, 2011; Cescatti et al., 2016). Prion-mediated spread of pathophysiological prominence to other cells leads 
to neurodegeneration. The best example of this mode of transmissible proteinopathy is CJD. The theory of exosomemediated propagation of prion disease resulted from the studies of Vella et al. (2007, 2008) which showed exosomeassociated protein-rich plasma (PrP; encoded by $P R N P$ ) in the CSF of sheep (Stahl and Prusiner, 1991). Later, Fevrier et al. (2004) reported release of both normal (PrPC) and pathogenic (PrPSc) prion protein in an exosome secreted by PrP-expressing cells. On one side where alteration of the exosome cargo and structure by PrPSc was reported (Bellingham et al., 2012; Coleman et al., 2012), upregulation of exosome secretion was found increasing the effectiveness of PrPSc (Kovacs, 2016).

\section{Alzheimer's Disease}

$\mathrm{AD}$ arises as a result of the extracellular deposition of amyloid- $\beta$ ( $\mathrm{A} \beta$; encoded by $A \beta P P$ ) fibrils and of abnormally phosphorylated tau protein (encoded by MAPT) in neurons (Iqbal et al., 2010; Murphy and LeVine, 2010; Bloom, 2014). A $\beta$ propagation via exosomes to extracellular milieu was reported by Rajendran et al. (2006) who observed cleavage of APP followed by secretion of $\beta$-amyloid in exosomes. Subsequently, secretions of the C-terminal part of APP was observed in vitro (Sharples et al., 2008) and in vivo (PerezGonzalez et al., 2012). Though, exosomes have been reported to induce the formation of neurotoxic oligomers of $A \beta$ (Yuyama et al., 2012; Joshi et al., 2014), they have also been reported to have a neuroprotective role of clearing toxic oligomeric species in exosomal lumen (Dinkins et al., 2014). Impaired $\mathrm{A} \beta$ clearance in $\mathrm{AD}$ patients and the neuronal and microglial exosome disposal of A $\beta$ (Yuyama et al., 2015) hints at the possibility of a dual clearance mode for $\mathrm{A} \beta$ in $\mathrm{AD}$.

Neurofibrillary tangles representing hyper-phosphorylated misfolded tau have been observed in the CSF of AD patients (Šimić et al., 2016). Exosomal secretion of tau is considered critical for the spread of tauopathy to different areas of the AD brain. Contrary to the dependence of tau propagation on the exosomal secretory pathway (Asai et al., 2015), recent studies on the role of exosomes in proteinopathies revealed regulation of Tau secretion by neuronal activities (Wu et al., 2016). Additional work is required to clarify the role played by exosomes in the progression of $\mathrm{AD}$.

\section{Parkinson's Disease}

Pre-synaptic $\alpha$-syn (encoded by SNCA) protein, which exists as an equilibrium between monomeric and oligomeric states, is a major component of Lewy bodies in PD (Spillantini et al., 1997). Presence of $\alpha$-Syn in synaptic vesicles suggests its involvement in synaptic vesicle processing (Vargas et al., 2014). $\alpha$-Syn induced conformational changes facilitates vesicle curvature during their production (Westphal and Chandra, 2013). Lee et al. (2005) reported compartmentalization of $\alpha$-syn promotes its misfolding, and Grey et al. (2015) reported acceleration of $\alpha$-syn aggregation in exosomes. Mutagenic and disease like factors favoring fibrillization, a pathogenic process in $\mathrm{PD}$, are thought to propagate in a prion-like process of $\alpha$-syn misfolding (Olanow and Brundin, 2013). Stuendl et al. (2016) reported the promotion of $\alpha$-syn aggregation by exosomal loaded $\alpha$-syn species isolated from CSF of PD patients.

\section{Amyotrophic Lateral Sclerosis}

Misfolding of $\mathrm{Cu} / \mathrm{Zn}$ SOD1 is a characteristic feature of the familiar and sporadic form of ALS (Bosco et al., 2010). Neuronal secretion of exosomes containing mutant SOD1 was found to transmit pathogenic traits to nearby neurons, such as, the misfolding of SOD1 (Gomes et al., 2007). Exosomes of astrocytic origin loaded with SOD1 show selective toxicity to neurons (Basso et al., 2013) and help establish the exosome-mediated pathogenic behavior of mutant SOD1 in ALS.

TDP-43 is a highly conserved nuclear protein (encoded by $T A R D B P$ ), and is another entity involved in ALS. Its pathogenic mechanisms include cytoplasmic mis-localization, misfolding followed by aggregation, and inclusion formation (Scotter et al., 2015). Dipeptide repeat proteins (DPRs) represent unconventional translation product of C9ORF72. Studies indicate an association between TDP-43 and DPRs resulting in the release and transport of exosomes, which supports the notion of exosome-based disease spread (Ding et al., 2015; Westergard et al., 2016).

\section{FUNCTIONAL ASPECTS OF EXOSOMES}

\section{Exosomes in Disease Diagnosis}

The progressive accumulation of protein aggregates (Brettschneider et al., 2013) and lack of sensitive biomarkers (Poste, 2011) hamper the development of disease-specific treatments for neurodegenerative diseases. Though protein aggregates can be detected in CSF and blood, their extremely low levels limit their usefulnesses as potent biomarkers of neurodegenerative diseases (Blennow and Zetterberg, 2015). Furthermore, low amounts of nucleic acid entities also limit their usefulnesses as biomarkers. Given these limitations, the focus for biomarkers in neurodegenerative diseases has shifted from proteins to the vesicular constituents of biofluids. In addition to the surface localizations of specific proteins, the presence of disease-specific molecular signatures in exosomes makes them strong diagnostic candidates. As they protect their cargoes from degradation (Théry et al., 2002; Chiasserini et al., 2014), screening exosomes in CSF and serum offers a means of identifying their cellular origins and thus provides insights of cellular and pathogenic processes going in CNS. Given evidence of their secretion into CNS (Thompson et al., 2016), it is possible that screening vesicular entities of CSF for vesicle associated membrane protein-2 and enolase (neuron specific markers), integrin $\alpha-\mathrm{M}$ (microglia specific marker) and transmembrane protein 132D (oligodendrocyte marker) could be used to detect neurodegenerative diseases. A good example of diseasespecific molecular signatures in exosomes is provided by exosomes produced by tumor cells in brain that displays of immunosuppressive and oncogenic factors (van der Vos et al., 2011) 


\section{Exosomes and Therapeutics}

The ability of exosomes to cross the blood-brain barrier (BBB) and pass through interstitial fluid into CSF has highlighted their use as drug delivery vehicles targeting the CNS. Systemic administration of exosomes with an siRNA cargo was utilized for drug delivery to the brains of mice (Alvarez-Erviti et al., 2011; Cooper et al., 2014), and the intranasal administration of exosomes loaded with an anti-inflammatory drug was also used for drug delivery to the mouse CNS (Zhuang et al., 2011). Though actual transport routes remain elusive, exosomes have great potential for the delivery of therapeutic RNAs, proteins and small molecules.

\section{Delivery of Therapeutic RNA}

The abilities of exosomes to transport nucleic acid cargoes (siRNA, miRNA) under physiological and pathological condition have increased interest in exploiting them as drug delivery vehicles and for genetic therapy. This ability is adopted to alter the expressions of genes via the bindings of siRNA or miRNA to complementary mRNA sequences thereby controlling gene expression at the post transcriptional level (Bartel, 2009; Ha et al., 2016). Furthermore, exosomes improve the stabilities of their contents in the systemic circulation and extracellular space, and thus, increase efficacies of delivery. Alvarez-Erviti et al. (2011) demonstrated the therapeutic advantages of exosome based siRNA delivery to mouse brain. They engineered surface localized Lamp2b protein to rabies glycoprotein to assist targeted delivery of therapeutic cargo to brain, and successfully delivered therapeutic GAPDH siRNA to neurons, microglia and oligodendrocytes in the brain. In addition, this study also provided insights regarding their utilization for the delivery of therapeutics to other tissues.

\section{Delivery of Therapeutic Proteins}

In addition to the delivery of RNA, exosome-based therapeutic protein delivery has also been shown to be beneficial in PD. Characterized by diminished SOD1 and catalase levels (Ambani et al., 1975), reactive oxygen species (ROS) overproduction causes the activation and inflammation of microglia in brain. Therapeutic delivery of catalase loaded into exosomes successfully crossed the BBB and inhibited neurodegeneration (Haney et al., 2015), and improved disease state in PD.

\section{Delivery of Small Therapeutic Molecules}

Knowing that efficiency of a drug depends on functional transport across the $\mathrm{BBB}$, strategies, such as, delivery as nano-formulations and PEGylated drugs, were commonly employed for targeted drug delivery (Yoshida et al., 1992; Veronese et al., 2002; Agrawal et al., 2014). However, delivery as nano-formulations was discontinued for toxicity reasons and rapid clearance by the mononuclear phagocyte system (MPS), while PEGylated drugs were discontinued because PEGylation reduced target-drug interaction, and thus, affected distribution in the brain. Exosome employment improves small molecule transport across the BBB transport because MPS clearance rates are lower for nano-delivery systems. Sun et al. (2010) adopted an exosomal strategy to deliver curcumin (an anti-inflammatory that reduces the productions of inflammatory cytokines like tumor necrosis factor- $\alpha$ (TNF- $\alpha$ ) and interleukin-6 (IL-6)) in brain. Exosomal curcumin delivery increased the solubility, stability and bioavailability of curcumin. Zhuang et al. (2011) followed this by co-administering curcumin and JS1124 (an activator of Stat3 inhibitor) to reduce production of inflammatory cytokines in brain (Sun et al., 2010), and a similar approach was adopted to deliver doxorubicin and paclitaxel across the BBB (Tian et al., 2014; Yang et al., 2015). In addition, Sun et al. (2010) reported that intranasal administration of endosomal GL26 suppressed glioma growth by increasing their microglial uptake. The therapeutic efficiencies of drugs observed in animal models indicate the potential of exosomes for the delivery of drugs across $\mathrm{BBB}$ to combat neurodegenerative disorders and brain tumors.

\section{EXOSOME ENGINEERING}

A large number of studies have been performed on the exosomal delivery of therapeutic molecules, but comparatively little effort has been directed toward engineering exosomes for the targetspecific deliveries of therapeutic cargoes. The prerequisite for targeted delivery of therapeutic molecules in different diseases is achieved by surface engineering of targeted peptide or protein on exosomes. Bioengineering of exosomes aimed at achieving correct insertion and avoiding peptide cleavage, results in the expressions of target peptides as fusion to signal peptide of lysosomal associated membrane protein-2b (Lamp-2b). A good example for this phenomena is provided by rabies viral glycoprotein (RVG) and iRGD peptides, which when engineered to exosomes of immature dendritic cells aided targeting of brain and tumor tissues (Alvarez-Erviti et al., 2011; Tian et al., 2014). Bioengineering was found to enhance the cellular uptakes of exosomes, and thereby increase the specificity of treatment in tissues of interest. For example, the surface expression of folate receptor- $\alpha(\mathrm{FR} \alpha)$ on choroid plexus epithelial cell derived exosomes was found to direct its cargo to brain parenchymal cells through choroid plexus (Grapp et al., 2013). Target peptide engineering facilitating delivery of drugs to brain tissues on crossing $\mathrm{BBB}$ or through choroid plexus, holds considerable promise in terms of overcoming the shortcomings of delivering drugs to brain (Alvarez-Erviti et al., 2011; Grapp et al., 2013). The specific cellular characters of exosomes add advantage for target specific delivery of therapeutic cargo.

\section{CONCLUSION}

Exosomes are nano-vesicles produced by diverse cell types and perform a multitude of functions in different cellular backgrounds. Although they have been mainly studied in the context of cell-to-cell communication, the surface localizations of specific proteins on exosomes and their disease specific molecular signatures makes them strong candidates for disease diagnosis. Furthermore, their abilities to transport proteins and nucleic acids goes well for their potential exploitation as drugs delivery agents. Because of the range of prospective application offered by exosomes, future work in this area seems necessary; 
to formulate robust and reproducible extraction protocols, to provide clearer understanding of the pathways involved in the biogenesis of exosomes and the loading of targeted therapeutic moieties, and to identify strategies for engineering exosomes that are capable target-specific drug delivery.

\section{AUTHOR CONTRIBUTIONS}

IC, TSA and ATJ conceived the idea. ATJ and MAM contributed to writing of the manuscript. ATJ, SR, HRY and EJL proofread the contents for upgradation and prepared the figures.

\section{REFERENCES}

Agrawal, U., Sharma, R., Gupta, M., and Vyas, S. P. (2014). Is nanotechnology a boon for oral drug delivery? Drug Discov. Today 19, 1530-1546. doi: 10.1016/j. drudis.2014.04.011

Alvarez-Erviti, L., Seow, Y., Yin, H., Betts, C., Lakhal, S., and Wood, M. J. (2011). Delivery of siRNA to the mouse brain by systemic injection of targeted exosomes. Nat. Biotechnol. 29, 341-345. doi: 10.1038/nbt.1807

Ambani, L. M., Van Woert, M. H., and Murphy, S. (1975). Brain peroxidase and catalase in Parkinson disease. Arch. Neurol. 32, 114-118. doi: 10.1001/archneur. 1975.00490440064010

Asai, H., Ikezu, S., Tsunoda, S., Medalla, M., Luebke, J., Haydar, T., et al. (2015). Depletion of microglia and inhibition of exosome synthesis halt tau propagation. Nat. Neurosci. 18, 1584-1593. doi: 10.1038/nn.4132

Bang, C., and Thum, T. (2012). Exosomes: new players in cell-cell communication. Int. J. Biochem. Cell Biol. 44, 2060-2064. doi: 10.1016/j.biocel.2012.08.007

Baranyai, T., Herczeg, K., Onódi, Z., Voszka, I., Módos, K., Marton, N., et al. (2015). Isolation of exosomes from blood plasma: qualitative and quantitative comparison of ultracentrifugation and size exclusion chromatography methods. PLoS One 10:e0145686. doi: 10.1371/journal.pone.0145686

Bartel, D. P. (2009). MicroRNAs: target recognition and regulatory functions. Cell 136, 215-233. doi: 10.1016/j.cell.2009.01.002

Basso, M., Pozzi, S., Tortarolo, M., Fiordaliso, F., Bisighini, C., Pasetto, L., et al. (2013). Mutant copper-zinc superoxide dismutase (SOD1) induces protein secretion pathway alterations and exosome release in astrocytes: implications for disease spreading and motor neuron pathology in amyotrophic lateral sclerosis. J. Biol. Chem. 288, 15699-15711. doi: 10.1074/jbc.M112. 425066

Bellingham, S. A., Coleman, B. M., and Hill, A. F. (2012). Small RNA deep sequencing reveals a distinct miRNA signature released in exosomes from prion-infected neuronal cells. Nucleic Acids Res. 40, 10937-10949. doi: 10.1093/nar/gks832

Bianco, F., Perrotta, C., Novellino, L., Francolini, M., Riganti, L., Menna, E., et al. (2009). Acid sphingomyelinase activity triggers microparticle release from glial cells. EMBO J. 28, 1043-1054. doi: 10.1038/emboj.2009.45

Blennow, K., and Zetterberg, H. (2015). Understanding biomarkers of neurodegeneration: ultrasensitive detection techniques pave the way for mechanistic understanding. Nat. Med. 21, 217-219. doi: 10.1038/ nm.3810

Bloom, G. S. (2014). Amyloid- $\beta$ and tau: the trigger and bullet in Alzheimer disease pathogenesis. JAMA Neurol. 71, 505-508. doi: 10.1001/jamaneurol.2013.5847

Bobrie, A., Colombo, M., Raposo, G., and Thery, C. (2011). Exosome secretion: molecular mechanisms and roles in immune responses. Traffic 12, 1659-1668. doi: 10.1111/j.1600-0854.2011.01225.x

Bosco, D. A., Morfini, G., Karabacak, N. M., Song, Y., Gros-Louis, F., Pasinelli, P., et al. (2010). Wild-type and mutant SOD1 share an aberrant conformation and a common pathogenic pathway in ALS. Nat. Neurosci. 13, 1396-1403. doi: $10.1038 / \mathrm{nn} .2660$

Brettschneider, J., Del Tredici, K., Toledo, J. B., Robinson, J. L., Irwin, D. J., Grossman, M., et al. (2013). Stages of pTDP-43 pathology in amyotrophic lateral sclerosis. Ann. Neurol. 74, 20-38. doi: 10.1002/ana.23937

\section{FUNDING}

The work was supported by the Creative Economy Leading Technology Development Program through the Gyeongsanbuk-Do and Gyeongbuk Science \& Technology Promotion Center of Korea (SF316001A).

\section{ACKNOWLEDGMENTS}

The authors extend their thanks to colleagues for their constructive suggestions, which undoubtedly improved the quality of this review.

Candelario, K. M., and Steindler, D. A. (2014). The role of extracellular vesicles in the progression of neurodegenerative disease and cancer. Trends Mol. Med. 20, 368-374. doi: 10.1016/j.molmed.2014.04.003

Cescatti, M., Saverioni, D., Capellari, S., Tagliavini, F., Kitamoto, T., Ironside, J., et al. (2016). Analysis of conformational stability of abnormal prion protein aggregates across the spectrum of creutzfeldt-jakob disease prions. J. Virol. 90, 6244-6254. doi: 10.1128/JVI.00144-16

Chiasserini, D., van Weering, J. R., Piersma, S. R., Pham, T. V., Malekzadeh, A., Teunissen, C. E., et al. (2014). Proteomic analysis of cerebrospinal fluid extracellular vesicles: a comprehensive dataset. J. Proteomics 106, 191-204. doi: 10.1016/j.jprot.2014.04.028

Clayton, A., Court, J., Navabi, H., Adams, M., Mason, M. D., Hobot, J. A., et al. (2001). Analysis of antigen presenting cell derived exosomes, based on immuno-magnetic isolation and flow cytometry. J. Immunol. Methods 247, 163-174. doi: 10.1016/s0022-1759(00)00321-5

Coleman, B. M., Hanssen, E., Lawson, V. A., and Hill, A. F. (2012). Prion-infected cells regulate the release of exosomes with distinct ultrastructural features. FASEB J. 26, 4160-4173. doi: 10.1096/fj.11-202077

Colombo, M., Raposo, G., and Théry, C. (2014). Biogenesis, secretion, and intercellular interactions of exosomes and other extracellular vesicles. Annu. Rev. Cell Dev. Biol. 30, 255-289. doi: 10.1146/annurev-cellbio-101512-122326

Cooper, J. M., Wiklander, P. B., Nordin, J. Z., Al-Shawi, R., Wood, M. J., Vithlani, M., et al. (2014). Systemic exosomal siRNA delivery reduced $\alpha$-synuclein aggregates in brains of transgenic mice. Mov. Disord. 29, 1476-1485. doi: 10.1002/mds.25978

Cosme, J., Liu, P. P., and Gramolini, A. O. (2013). The cardiovascular exosome: current perspectives and potential. Proteomics 13, 1654-1659. doi: $10.1002 /$ pmic. 201200441

Ding, X., Ma, M., Teng, J., Teng, R. K., Zhou, S., Yin, J., et al. (2015). Exposure to ALS-FTD-CSF generates TDP-43 aggregates in glioblastoma cells through exosomes and TNTs-like structure. Oncotarget 6, 24178-24191. doi: 10.18632/oncotarget.4680

Dinkins, M. B., Dasgupta, S., Wang, G., Zhu, G., and Bieberich, E. (2014). Exosome reduction in vivo is associated with lower amyloid plaque load in the 5XFAD mouse model of Alzheimer's disease. Neurobiol. Aging 35, 1792-1800. doi: 10.1016/j.neurobiolaging.2014.02.012

Fevrier, B., Vilette, D., Archer, F., Loew, D., Faigle, W., Vidal, M., et al. (2004). Cells release prions in association with exosomes. Proc. Natl. Acad. Sci. U S A 101, 9683-9688. doi: 10.1073/pnas.0308413101

Gomes, C., Keller, S., Altevogt, P., and Costa, J. (2007). Evidence for secretion of $\mathrm{Cu}, \mathrm{Zn}$ superoxide dismutase via exosomes from a cell model of amyotrophic lateral sclerosis. Neurosci. Lett. 428, 43-46. doi: 10.1016/j.neulet.2007.09.024

Grapp, M., Wrede, A., Schweizer, M., Hüwel, S., Galla, H. J., Snaidero, N., et al. (2013). Choroid plexus transcytosis and exosome shuttling deliver folate into brain parenchyma. Nat. Commun. 4:2123. doi: 10.1038/ncomms3123

Grey, M., Dunning, C. J., Gaspar, R., Grey, C., Brundin, P., Sparr, E., et al. (2015). Acceleration of $\alpha$-synuclein aggregation by exosomes. J. Biol. Chem. 290, 2969-2982. doi: 10.1074/jbc.M114.585703

Gui, Y., Liu, H., Zhang, L., Lv, W., and Hu, X. (2015). Altered microRNA profiles in cerebrospinal fluid exosome in Parkinson disease and Alzheimer disease. Oncotarget 6, 37043-37053. doi: 10.18632/oncotarget.6158 
Ha, D., Yang, N., and Nadithe, V. (2016). Exosomes as therapeutic drug carriers and delivery vehicles across biological membranes: current perspectives and future challenges. Acta Pharm. Sin. B 6, 287-296. doi: 10.1016/j.apsb.2016. 02.001

Haney, M. J., Klyachko, N. L., Zhao, Y., Gupta, R., Plotnikova, E. G., He, Z., et al. (2015). Exosomes as drug delivery vehicles for Parkinson's disease therapy. J. Control. Release 207, 18-30. doi: 10.1016/j.jconrel.2015.03.033

Haraszti, R. A., Didiot, M. C., Sapp, E., Leszyk, J., Shaffer, S. A., Rockwell, H. E., et al. (2016). High-resolution proteomic and lipidomic analysis of exosomes and microvesicles from different cell sources. J. Extracell. Vesicles 5:32570. doi: $10.3402 /$ jev.v5.32570

Harding, C., and Stahl, P. (1983). Transferrin recycling in reticulocytes: $\mathrm{pH}$ and iron are important determinants of ligand binding and processing. Biochem. Biophys. Res. Commun. 113, 650-658. doi: 10.1016/0006-291x(83)91776-x

Iqbal, K., Liu, F., Gong, C. X., and Grundke-Iqbal, I. (2010). Tau in Alzheimer disease and related tauopathies. Curr. Alzheimer Res. 7, 656-664. doi: $10.2174 / 156720510793611592$

Janas, T., Janas, M. M., and Sapoń, K. (2015). Mechanisms of RNA loading into exosomes. FEBS Lett. 589, 1391-1398. doi: 10.1016/j.febslet.2015.04.036

Johnstone, R. M., Adam, M., Hammond, J. R., Orr, L., and Turbide, C. (1987). Vesicle formation during reticulocyte maturation. Association of plasma membrane activities with released vesicles (exosomes). J. Biol. Chem. 262, 9412-9420.

Joshi, P., Turola, E., Ruiz, A., Bergami, A., Libera, D. D., Benussi, L., et al. (2014). Microglia convert aggregated amyloid- $\beta$ into neurotoxic forms through the shedding of microvesicles. Cell Death Differ. 21, 582-593. doi: 10.1038/cdd. 2013.180

Kalluri, R., and LeBleu, V. S. (2016). Discovery of double-stranded genomic DNA in circulating exosomes. Cold Spring Harb. Symp. Quant. Biol. 81, 275-280. doi: 10.1101/sqb.2016.81.030932

Keerthikumar, S., Gangoda, L., Liem, M., Fonseka, P., Atukorala, I., Ozcitti, C., et al. (2015). Proteogenomic analysis reveals exosomes are more oncogenic than ectosomes. Oncotarget 6, 15375-15396. doi: 10.18632/oncotarget.3801

Keller, S., Sanderson, M. P., Stoeck, A., and Altevogt, P. (2006). Exosomes: from biogenesis and secretion to biological function. Immunol. Lett. 107, 102-108. doi: 10.1016/j.imlet.2006.09.005

Kettenmann, H., Hanisch, U. K., Noda, M., and Verkhratsky, A. (2011). Physiology of microglia. Physiol. Rev. 91, 461-553. doi: 10.1152/physrev.00011.2010

Kovacs, G. G. (2016). Molecular pathological classification of neurodegenerative diseases: turning towards precision medicine. Int. J. Mol. Sci. 17:E189. doi: $10.3390 /$ ijms 17020189

Kupfer, L., Hinrichs, W., and Groschup, M. H. (2009). Prion protein misfolding. Curr. Mol. Med. 9, 826-835. doi: 10.2174/156652409789105543

Lee, H. J., Patel, S., and Lee, S. J. (2005). Intravesicular localization and exocytosis of $\alpha$-synuclein and its aggregates. J. Neurosci. 25, 6016-6024. doi: 10.1523/JNEUROSCI.0692-05.2005

Moore, R. A., Taubner, L. M., and Priola, S. A. (2009). Prion protein misfolding and disease. Curr. Opin. Struct. Biol. 19, 14-22. doi: 10.1016/j.sbi.2008. 12.007

Murphy, M. P., and LeVine, H. III (2010). Alzheimer's disease and the $\beta$-amyloid peptide. J. Alzheimers Dis. 19, 311-323. doi: 10.3233/JAD-2010-12212

Olanow, C. W., and Brundin, P. (2013). Parkinson's disease and $\alpha$ synuclein: is Parkinson's disease a prion-like disorder? Mov. Disord. 28, 31-40. doi: $10.1002 / \mathrm{mds} .25373$

Perez-Gonzalez, R., Gauthier, S. A., Kumar, A., and Levy, E. (2012). The exosome secretory pathway transports amyloid precursor protein carboxyl-terminal fragments from the cell into the brain extracellular space. J. Biol. Chem. 287, 43108-43115. doi: 10.1074/jbc.M112.404467

Polymenidou, M., and Cleveland, D. W. (2011). The seeds of neurodegeneration: prion-like spreading in ALS. Cell 147, 498-508. doi: 10.1016/j.cell.2011.10.011

Poste, G. (2011). Bring on the biomarkers. Nature 469, 156-157. doi: $10.1038 / 469156 a$

Prusiner, S. B. (1982). Novel proteinaceous infectious particles cause scrapie. Science 216, 136-144. doi: 10.1126/science.6801762

Rajendran, L., Honsho, M., Zahn, T. R., Keller, P., Geiger, K. D., Verkade, P., et al. (2006). Alzheimer's disease $\beta$-amyloid peptides are released in association with exosomes. Proc. Natl. Acad. Sci. U S A 103, 11172-11177. doi: 10.1073/pnas. 0603838103
Raposo, G., Nijman, H. W., Stoorvogel, W., Liejendekker, R., Harding, C. V., Melief, C. J., et al. (1996). B lymphocytes secrete antigen-presenting vesicles. J. Exp. Med. 183, 1161-1172. doi: 10.1084/jem.183.3.1161

Raposo, G., and Stoorvogel, W. (2013). Extracellular vesicles: exosomes, microvesicles, and friends. J. Cell Biol. 200, 373-383. doi: 10.1083/jcb. 201211138

Royo, F., Zuñiga-Garcia, P., Torrano, V., Loizaga, A., Sanchez-Mosquera, P., Ugalde-Olano, A., et al. (2016). Transcriptomic profiling of urine extracellular vesicles reveals alterations of $\mathrm{CDH} 3$ in prostate cancer. Oncotarget 7, 6835-6846. doi: 10.18632/oncotarget.6899

Scotter, E. L., Chen, H. J., and Shaw, C. E. (2015). TDP-43 proteinopathy and ALS: insights into disease mechanisms and therapeutic targets. Neurotherapeutics 12 , 352-363. doi: 10.1007/s13311-015-0338-x

Sharples, R. A., Vella, L. J., Nisbet, R. M., Naylor, R., Perez, K., Barnham, K. J., et al. (2008). Inhibition of $\gamma$-secretase causes increased secretion of amyloid precursor protein $\mathrm{C}$-terminal fragments in association with exosomes. FASEB J. 22, 1469-1478. doi: 10.1096/fj.07-9357com

Šimić, G., Babić Leko, M., Wray, S., Harrington, C., Delalle, I., JovanovMilošević, N., et al. (2016). Tau protein hyperphosphorylation and aggregation in Alzheimer's disease and other tauopathies and possible neuroprotective strategies. Biomolecules 6:6. doi: 10.3390/biom6010006

Skog, J., Würdinger, T., van Rijn, S., Meijer, D. H., Gainche, L., Sena-Esteves, M., et al. (2008). Glioblastoma microvesicles transport RNA and proteins that promote tumour growth and provide diagnostic biomarkers. Nat. Cell Biol. 10, 1470-1476. doi: 10.1038/ncb1800

Spillantini, M. G., Schmidt, M. L., Lee, V. M., Trojanowski, J. Q., Jakes, R., and Goedert, M. (1997). $\alpha$-synuclein in Lewy bodies. Nature 388, 839-840. doi: $10.1038 / 42166$

Stahl, N., and Prusiner, S. B. (1991). Prions and prion proteins. FASEB J. 5, 2799-2807.

Stuendl, A., Kunadt, M., Kruse, N., Bartels, C., Moebius, W., Danzer, K. M., et al. (2016). Induction of $\alpha$-synuclein aggregate formation by CSF exosomes from patients with Parkinson's disease and dementia with Lewy bodies. Brain 139, 481-494. doi: 10.1093/brain/awv346

Sun, D., Zhuang, X., Xiang, X., Liu, Y., Zhang, S., Liu, C., et al. (2010). A novel nanoparticle drug delivery system: the anti-inflammatory activity of curcumin is enhanced when encapsulated in exosomes. Mol. Ther. 18, 1606-1614. doi: $10.1038 / \mathrm{mt} .2010 .105$

Théry, C., Ostrowski, M., and Segura, E. (2009). Membrane vesicles as conveyors of immune responses. Nat. Rev. Immunol. 9, 581-593. doi: 10.1038/nri2567

Théry, C., Zitvogel, L., and Amigorena, S. (2002). Exosomes: composition, biogenesis and function. Nat. Rev. Immunol. 2, 569-579. doi: 10.1038/nri855

Thompson, A. G., Gray, E., Heman-Ackah, S. M., Mager, I., Talbot, K., Andaloussi, S. E., et al. (2016). Extracellular vesicles in neurodegenerative disease-pathogenesis to biomarkers. Nat. Rev. Neurol. 12, 346-357. doi: 10.1038/nrneurol.2016.68

Tian, Y., Li, S., Song, J., Ji, T., Zhu, M., Anderson, G. J., et al. (2014). A doxorubicin delivery platform using engineered natural membrane vesicle exosomes for targeted tumor therapy. Biomaterials 35, 2383-2390. doi: 10.1016/j. biomaterials.2013.11.083

van Balkom, B. W., Eisele, A. S., Pegtel, D. M., Bervoets, S., and Verhaar, M. C. (2015). Quantitative and qualitative analysis of small RNAs in human endothelial cells and exosomes provides insights into localized RNA processing, degradation and sorting. J. Extracell. Vesicles 4:26760. doi: 10.3402/jev.v4.26760

van der Vos, K. E., Balaj, L., Skog, J., and Breakefield, X. O. (2011). Brain tumor microvesicles: insights into intercellular communication in the nervous system. Cell. Mol. Neurobiol. 31, 949-959. doi: 10.1007/s10571-011-9697-y

Vargas, K. J., Makani, S., Davis, T., Westphal, C. H., Castillo, P. E., and Chandra, S. S. (2014). Synucleins regulate the kinetics of synaptic vesicle endocytosis. J. Neurosci. 34, 9364-9376. doi: 10.1523/JNEUROSCI.478713.2014

Vella, L. J., Greenwood, D. L., Cappai, R., Scheerlinck, J. P., and Hill, A. F. (2008). Enrichment of prion protein in exosomes derived from ovine cerebral spinal fluid. Vet. Immunol. Immunopathol. 124, 385-393. doi: 10.1016/j.vetimm.2008. 04.002

Vella, L. J., Sharples, R. A., Lawson, V. A., Masters, C. L., Cappai, R., and Hill, A. F. (2007). Packaging of prions into exosomes is associated with a novel pathway of PrP processing. J. Pathol. 211, 582-590. doi: 10.1002/path.2145 
Veronese, F. M., Caliceti, P., Schiavon, O., and Sergi, M. (2002). Polyethylene glycol-superoxide dismutase, a conjugate in search of exploitation. Adv. Drug Deliv. Rev. 54, 587-606. doi: 10.1016/s0169-409x(02) 00029-7

Vlassov, A. V., Magdaleno, S., Setterquist, R., and Conrad, R. (2012). Exosomes: current knowledge of their composition, biological functions and diagnostic and therapeutic potentials. Biochim. Biophys. Acta 1820, 940-948. doi: 10.1016/j.bbagen.2012.03.017

Wang, S., Cesca, F., Loers, G., Schweizer, M., Buck, F., Benfenati, F., et al. (2011). Synapsin I is an oligomannose-carrying glycoprotein, acts as an oligomannose-binding lectin and promotes neurite outgrowth and neuronal survival when released via glia-derived exosomes. J. Neurosci. 31, 7275-7290. doi: 10.1523/JNEUROSCI.6476-10.2011

Westergard, T., Jensen, B. K., Wen, X., Cai, J., Kropf, E., Iacovitti, L., et al. (2016). Cell-to-cell transmission of dipeptide repeat proteins linked to $c 90 r f 72$ ALS/FTD. Cell Rep. 17, 645-652. doi: 10.1016/j.celrep.2016.09.032

Westphal, C. H., and Chandra, S. S. (2013). Monomeric synucleins generate membrane curvature. J. Biol. Chem. 288, 1829-1840. doi: 10.1074/jbc.m112. 418871

Wu, J. W., Hussaini, S. A., Bastille, I. M., Rodriguez, G. A., Mrejeru, A., Rilett, K., et al. (2016). Neuronal activity enhances tau propagation and tau pathology in vivo. Nat. Neurosci. 19, 1085-1092. doi: 10.1038/nn.4328

Yang, T., Martin, P., Fogarty, B., Brown, A., Schurman, K., Phipps, R., et al. (2015). Exosome delivered anticancer drugs across the blood-brain barrier for brain cancer therapy in Danio rerio. Pharm. Res. 32, 2003-2014. doi: 10.1007/s11095014-1593-y

Yoshida, K., Burton, G. F., McKinney, J. S., Young, H., and Ellis, E. F. (1992). Brain and tissue distribution of polyethylene glycol-conjugated superoxide dismutase in rats. Stroke 23, 865-869. doi: 10.1161/01.str.23.6.865
Yuyama, K., Sun, H., Mitsutake, S., and Igarashi, Y. (2012). Sphingolipidmodulated exosome secretion promotes clearance of amyloid- $\beta$ by microglia. J. Biol. Chem. 287, 10977-10989. doi: 10.1074/jbc.M111.324616

Yuyama, K., Sun, H., Usuki, S., Sakai, S., Hanamatsu, H., Mioka, T., et al. (2015). A potential function for neuronal exosomes: sequestering intracerebral amyloid$\beta$ peptide. FEBS Lett. 589, 84-88. doi: 10.1016/j.febslet.2014.11.027

Zhang, J., Li, S., Li, L., Li, M., Guo, C., Yao, J., et al. (2015). Exosome and exosomal microRNA: trafficking, sorting and function. Genomics Proteomics Bioinformatics 13, 17-24. doi: 10.1016/j.gpb.2015.02.001

Zhuang, X., Xiang, X., Grizzle, W., Sun, D., Zhang, S., Axtell, R. C., et al. (2011). Treatment of brain inflammatory diseases by delivering exosome encapsulated anti-inflammatory drugs from the nasal region to the brain. Mol. Ther. 19, 1769-1779. doi: 10.1038/mt.2011.164

Zonneveld, M. I., Brisson, A. R., van Herwijnen, M. J. C., Tan, S., van de Lest, C. H. A., Redegeld, F. A., et al. (2014). Recovery of extracellular vesicles from human breast milk is influenced by sample collection and vesicle isolation procedures. J. Extracell. Vesicles 3:24215. doi: 10.3402/jev.v3.24215

Conflict of Interest Statement: The authors declare that the research was conducted in the absence of any commercial or financial relationships that could be construed as a potential conflict of interest.

Copyright (C) 2017 Jan, Malik, Rahman, Yeo, Lee, Abdullah and Choi. This is an open-access article distributed under the terms of the Creative Commons Attribution License (CC BY). The use, distribution or reproduction in other forums is permitted, provided the original author(s) or licensor are credited and that the original publication in this journal is cited, in accordance with accepted academic practice. No use, distribution or reproduction is permitted which does not comply with these terms. 